REGETUFSM GUERRA, KLINGER, DÖRR, v(10), no 10, p. 2327-2339, JAN-ABR, 2013.

Rev. Elet. em Gestão, Educação e Tecnologia Ambiental (e-ISSN: 2236-1170)

\title{
A DINÂMICA DA PRODUÇÃO DE FUMO EM VERA CRUZ- RS
}

\section{THE DYNAMICS OF PRODUCTION OF TOBACCO CULTURE IN THE VERA CRUZ-RS.}

\author{
Renata Rojas Guerra ${ }^{1}$, Ana Carolina Kohlrausch Klinger ${ }^{2}$, Andréa Cristina Dörr ${ }^{3}$ \\ ${ }^{1}$ Estudante de graduação do curso de Ciências Economicas da Universidade Federal de Santa Maria - UFSM, E-mail: \\ renata.rojasg@gmail.com \\ ${ }^{2}$ Graduada em Zootecnia pela Universidade Federal de Santa Maria - UFSM. E-mail: aninhaklinger@zootecnista.com.br \\ ${ }^{3}$ Professora, Doutora e Pesquisadora da Universidade Federal de Santa Maria.
}

http://dx.doi.org/10.5902/223611708758

\begin{abstract}
RESUMO
Este trabalho objetivou caracterizar a dinâmica produtiva da cultura de fumo no município de Vera Cruz - RS. Foi identificado o papel dos fumicultores dentro do mercado, bem como sua relação com as empresas beneficiadoras de tabaco. Para tanto, utilizou-se de uma análise de abordagem quantitativa, cujos dados foram obtidos através da aplicação de 22 formulários semi-estruturados compostos por perguntas fechadas e abertas. Assim, foi possível constatar que a produção fumageira da região ocorre por meio de uma produção familiar, intensiva e semi-intensiva de mão de obra e estruturada em minifúndios, em contrapartida, as empresas beneficiadoras de tabaco constituem uma estrutura de mercado oligopolizada. Já as relações contratuais ocorrem por meio do processo de integração entre fumicultor e agroindústria. Este cenário, além de deixar o fumicultor mais vulnerável aos choques de mercado, o torna altamente dependente do capital agroindustrial.
\end{abstract}

Palavras-chave: agricultura familiar, fumo, nova economia institucional, sistemas agroindustriais

\begin{abstract}
This paper aims to characterize the productive dynamic of tobacco culture in Vera Cruz - RS. Has been identified the role of growers in the marketplace, as well as its relationship with the tobacco manufacturing companies. For this purpose, we used an analysis of a quantitative approach; the data were obtained through the application of 22 semistructured forms consisting of closed and open questions. Thus, it was found that tobacco production in the region occurs through a household production, labor-intensive and structured small farms, while in contrast, the tobacco manufacturing companies constitute an oligopolistic market structure. Having contractual relations occur through the process of integration between tobacco farmer and agribusiness. This scenario makes the tobacco farmer more vulnerable to market shocks and makes it highly dependent on the agro-industrial capital.
\end{abstract}

Key-words: Family farming, tobacco, agroindustrial systems, new institucional economics 


\section{REGETUFSM}

GUERRA ,KLINGER, DÖRR, v(10), no 10, p. 2327-2339, JAN-ABR, 2013.

Rev. Elet. em Gestão, Educação e Tecnologia Ambiental (e-ISSN: 2236-1170)

\section{INTRODUÇÃO}

A cultura de fumo e derivados desempenha um papel de extrema relevância na balança comercial brasileira. Além do país ser o maior exportador do produto desde 1993, o setor é o quinto maior contribuinte para o crescimento do total de exportações agroindustriais brasileiras entre 2004 e 2010 segundo o Mapa (2011). Ademais, com uma produção de 867.210 toneladas na safra 2010/2011, o Brasil consolida-se como o segundo maior produtor mundial de fumo, perdendo apenas para a China.

De acordo com Mapa (2011), projeta-se que a quantidade produzida no Brasil aumente mais de 100 mil toneladas nos próximos 10 anos. Entretanto, a despeito da magnitude da cadeia produtiva de fumo brasileira, bem como do alto nível de desenvolvimento no âmbito de logística de compra e de transporte do produto, a fumicultura no país é basicamente formada pela agricultura familiar. Sendo uma produção pulverizada, estima-se que haja cerca de 223 mil famílias envolvidas diretamente na cultura de fumo no Brasil.

Conforme Afubra (2012), apenas nos três estados da região sul do país há 720 municípios que apresenta a fumicultura como base de suas relações econômicas e sociais. Esta realidade conjuntural se deve ao fato de que, em média, $68 \%$ da renda dos habitantes destas localidades dependem exclusivamente da produção de fumo. Este é o caso da região do Vale do Rio Pardo RS, a qual está historicamente vinculada à produção de fumo, sendo as demais culturas direcionadas exclusivamente para a subsistência, com eventuais vendas de excedentes (KARNOPP, 2003).

Porém, devido a crescentes preocupações acerca dos malefícios causados à saúde dos fumantes, os governos de vários países têm investido em ações antitabagismo, o que impacta negativamente a produção fumageira (BOEIRA, 2006). Neste sentido, organizações como a AFUBRA têm realizado campanhas no intuito de orientar os produtores a diversificar sua produção. Entretanto, por ser esta uma das poucas cadeias produtivas compatíveis com a estrutura de minifúndios e devido ao seu caráter intensivo em mão de obra, muitos produtores podem encontrar dificuldades em migrar para outras culturas que exigem maiores recursos (SCHOENHALS et al., 2009).

É neste contexto que se insere o presente estudo, o qual, tendo em vista a importância da produção fumageira para as famílias do município de Vera Cruz - RS, localizado no Vale do Rio Pardo - RS, tem por objetivo caracterizar a dinâmica produtiva da cultura de fumo na região. Mais especificamente, pretende-se identificar o papel dos fumicultores dentro do mercado em que estão inseridos, bem como sua relação com as empresas beneficiadoras de tabaco. Além disso, a determinação da viabilidade econômica e custo de oportunidade inerentes à atividade também se insere no escopo do presente estudo.

Para tanto, leva-se em consideração a hipótese de que a comercialização do fumo produzido no município ocorre na forma de integração. Trabalhos realizados por Cavalcante e Pinto (2004) e Boeira (2006) afirmam que a fumicultura brasileira funciona como um "sistema 


\section{REGETUFSM}

GUERRA ,KLINGER, DÖRR, v(10), no 10, p. 2327-2339, JAN-ABR, 2013.

Rev. Elet. em Gestão, Educação e Tecnologia Ambiental (e-ISSN: 2236-1170)

integrado" composto basicamente por empresas transnacionais que operam com a produção, processamento, beneficiamento e comercialização do fumo em folha e de seus produtos derivados. Resta, entretanto, atestar se este cenário se sustenta para o município de Vera Cruz RS.

Caso tal hipótese seja corroborada, implicará numa situação em que as indústrias fumageiras disponibilizam crédito, assistência técnica e garantia de compra aos produtores. Entretanto, conforme Silva (2011), neste tipo de sistema produtivo os agricultores, apesar de permanecerem proprietários dos seus meios de produção, encontram-se numa situação de ependência e subordinação ao capital agroindustrial.

\section{METODOLOGIA}

Este estudo trata-se de uma análise descritiva, correlacional, de corte transversal e abordagem quantitativa desenvolvido com a população residente nos distritos de Linha Capão e Vila Progresso do município Vera Cruz - RS, situado no Vale do Rio Pardo, região central do Estado do Rio Grande do Sul. Esta localidade, conforme dados da AFUBRA (2012), possui uma população de 2.498 produtores rurais. Desse conjunto, foi selecionada uma amostra aleatória cujo tamanho é definido através da seguinte fórmula, Schneider (2004):

$$
n=\frac{\left(t_{\delta, \frac{\alpha}{2}}\right)^{2} \times s^{2} \times N}{e_{0}^{2}(N-1)+\left(t_{\delta, \frac{\alpha}{2}}\right)^{2} \times s^{2}}
$$

Onde:

$\mathrm{n}$ = tamanho mínimo da amostra calculada;

$t_{\delta, \frac{\alpha}{2},=}$ valor de $t_{t a b}$ admitindo $\alpha=5 \%$;

$s^{2}=$ variância obtida através da amostra piloto;

$\mathrm{N}$ = tamanho da população;

$\mathrm{e}_{0}{ }^{2}=$ quadrado do erro amostral, obtido com os dados da amostra piloto

A partir da equação (1), chegou-se a uma amostra mínima de 22 produtores, a partir da qual foi conduzida a presente análise. Os dados primários foram obtidos por meio da aplicação de um formulário semiestruturado composto por perguntas fechadas e abertas. Neste, foram abordadas questões relativas ao perfil sócio-econômico e hábitos de vida dos proprietários rurais 


\section{REGETUFSM}

GUERRA ,KLINGER, DÖRR, v(10), no 10, p. 2327-2339, JAN-ABR, 2013.

Rev. Elet. em Gestão, Educação e Tecnologia Ambiental (e-ISSN: 2236-1170)

em questão. Além disso, foram levantadas informações acerca dos registros contábeis, gerenciais e de infra-estrutura dos empreendimentos da região. A coleta dos dados ocorreu entre os meses de julho e agosto de 2011.

Após a coleta, os dados foram tabulados no programa Software Statistical Package for Social Science (SPSS), para análise estatística descritiva e inferencial, onde são computados os resultados das estatísticas sumárias, bem como das distribuições de frequência individual para variáveis de interesse. Tais análises fornecem informações relevantes acerca do comportamento dos dados, permitindo perceber as dimensões de suas variações.

\section{RESSULTADOS E DISCUSSÕES}

Nesta sessão são apresentadas informações que permitem analisar o ambiente estrutural vivenciado pelos fumicultores do município de Vera Cruz - RS, bem como a relação dos mesmos com as empresas beneficiadoras de tabaco.

Na Tabela 1 estão contidas as distribuições de frequência segundo as características da produção, as quais evidenciam uma situação em que $61,90 \%$ dos fumicultores afirmaram serem proprietários de toda a terra cultivada, enquanto que, quando abordados a respeito do tempo que estão inseridos na atividade, todos produtores relatram cultivar o tabaco por pelo menos 21 anos. Destes, apenas $23,81 \%$ fazem uso de terras com área total superior a 20 hectares, sendo que, dentre as propriedades que compõem a amostra, a de maior extensão é formada por somente 45 hectares. No que diz respeito à mecanização da produção, menos de $43 \%$ dos fumicultores declarou possuir ao menos um trator com menos de 10 anos.

Considerando tais informações, torna-se possível constatar que a produção fumageira da região ocorre por meio de uma produção familiar, intensiva em mão de obra e estruturada na forma de minifúndios. Fato que converge com as observações realizadas no trabalho de Vogt (1997), o qual destacou não apenas as características acima descritas, mas também a forte influência da tradição por parte das famílias fumicultoras.

Tabela 1. Distribuição de frequência de acordo com as variáveis de infra-estrutura

\begin{tabular}{lll}
\hline \multirow{2}{*}{ Variáveis } & \multicolumn{2}{c}{ Frequencia } \\
\cline { 2 - 3 } & Absoluta $(n=21)$ & Relativa (\%)
\end{tabular}

Tempo de fumicultura (em anos)

21 a 30 
REGEXITFM

GUERRA ,KLINGER, DÖRR, v(10), no 10, p. 2327-2339, JAN-ABR, 2013.

Rev. Elet. em Gestão, Educação e Tecnologia Ambiental (e-ISSN: 2236-1170)

31 a 40

41 a 50

3

$14,29 \%$

51 ou mais

9

$42,86 \%$

Não respondeu

1

$4,76 \%$

Area da propriedade (ha)

Até 2

$14,29 \%$

De 3 a 6

De 7 a 10

De 11 a 15

De 16 a 20

mais de 20

Relação de posse da terra

Própria

$61,90 \%$

Arrendada

Arrendada e Parceiro

Própria e Arrendada

Própria e Parceiro

Não respondeu

\section{Possui trator}

Não

1 novo*

1 antigo**

1 novo e 1 antigo

2 antigos 
Rev. Elet. em Gestão, Educação e Tecnologia Ambiental (e-ISSN: 2236-1170)

As Figuras 1 e 2 também colaboram para a compreensão da relação entre os minifundiários de Vera Cruz - RS e o cultivo do fumo como sua principal fonte de renda. Na primeira, é evidenciada a relação entre a área total da propriedade e a área dedicada exclusivamente à cultura.

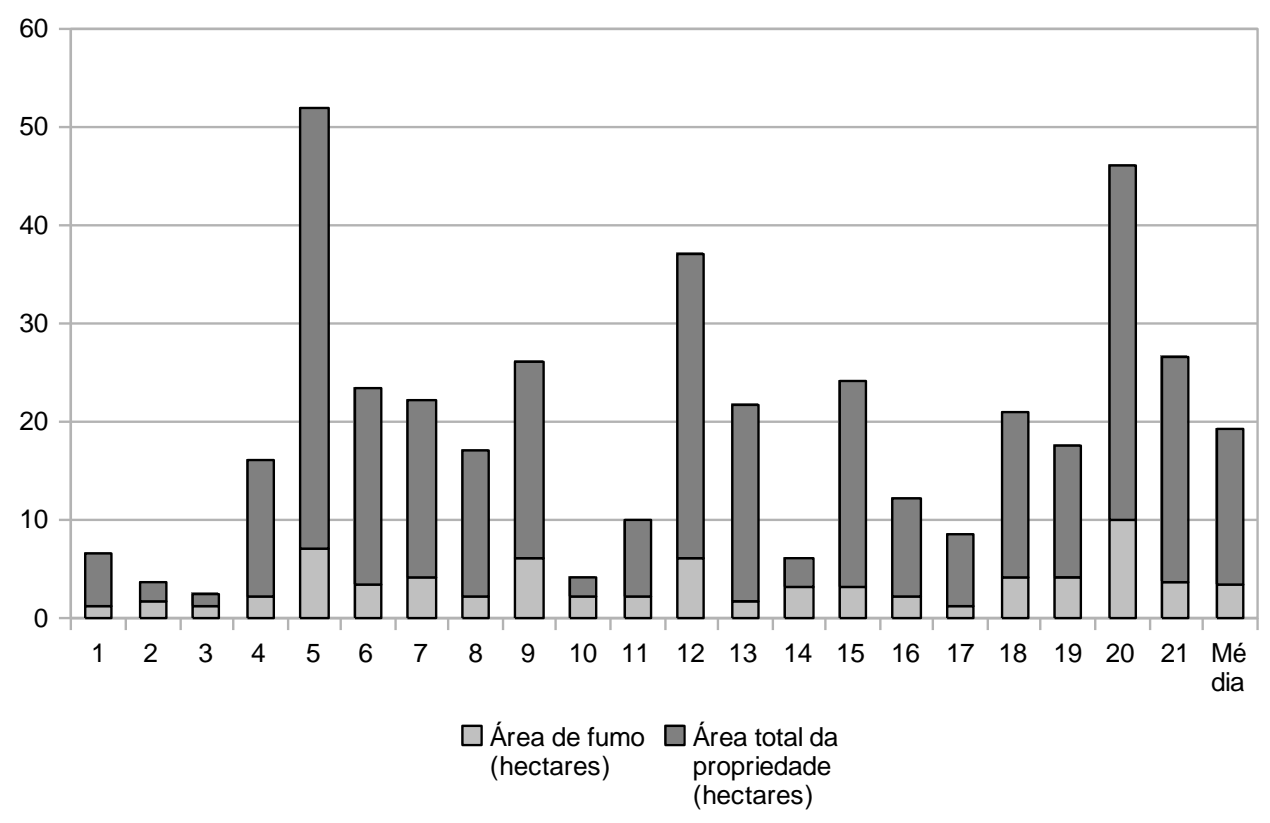

Figura 1. Relação entre a área total da propriedade e a área dedicada exclusivamente à fumicultura. Foram consideradas apenas 21 observações pois um entrevistados não soube responder à questão Fonte: Elaborado pelos autores a partir dos dados primários da pesquisa.

Já a Figura 2, enfatiza a proporção da renda oriunda da fumicultura na composição no total de rendimentos das famílias residentes na região.

Como é possível observar, há uma forte correlação entre a produção fumageira e a situação econômico-financeira dos produtores rurais do município em análise. É interessante destacar que, em geral, os produtores não dedicam um percentual elevado de sua área total na produção fumageira (Figura 1) apesar da cultura de fumo representar uma parte significativa da renda da propriedade (Figura 2). 
Rev. Elet. em Gestão, Educação e Tecnologia Ambiental (e-ISSN: 2236-1170)

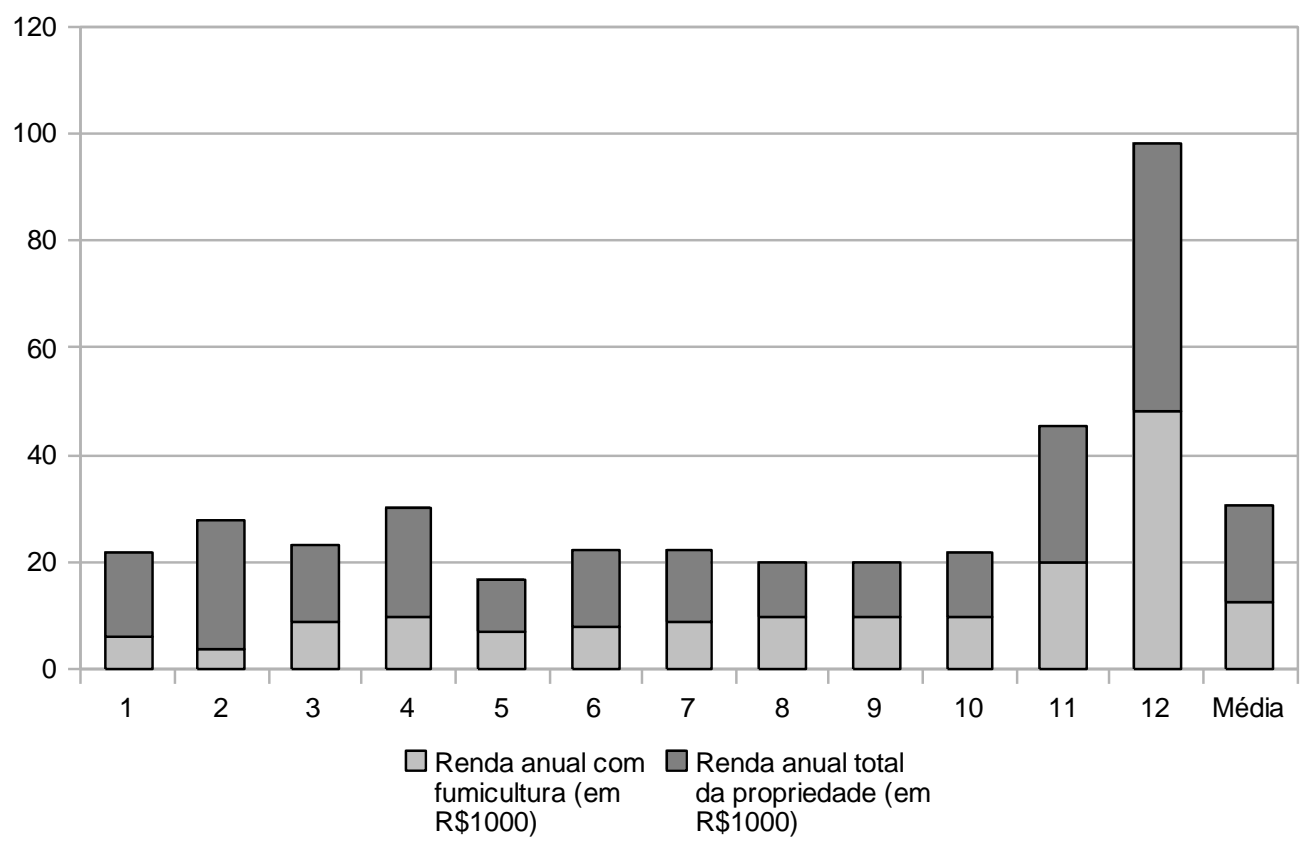

Figura 2. Relação entre a renda total dos entrevistados e a renda oriunda exclusivamente da fumicultura. Foram consideradas apenas 12 observações pois os demais entrevistados não souberam responder à questão. Fonte:Elaborado pelos autores a partir dos dados primários da pesquisa.

Ao tratar do custo de oportunidade envolvido na cadeia produtiva em questão, os dados da pesquisa revelam que todos os produtores já cogitaram a hipótese de abandonar o cultivo de fumo, embora $42,86 \%$ destes admitem a necessidade de permanecer neste ramo devido à sua alta rentabilidade (Tabela 2). Neste sentido, o trabalho de Schoenhals et al. (2009), ao mencionar que "os pequenos agricultores optaram pela cultura do tabaco em função da lucratividade obtida, a qual não seria alcançada com outras culturas em função da pequena área dos produtores" apontou uma realidade semelhante para os fumicultores residentes no município de Vera-Cruz.

Tabela 2. Distribuição de frequência de acordo com as variáveis de custo de oportunidade

\section{Frequencia}

Variáveis
Absoluta $(n=21)$
Relativa (\%)

\section{Deixaria de produzir fumo}

Sim. Devido ao baixo preço pago pelas

indústrias e desvalorização do produto. 
REGETfUFSM GUERRA, KLINGER, DÖRR, v(10), no 10, p. 2327-2339, JAN-ABR, 2013.

Rev. Elet. em Gestão, Educação e Tecnologia Ambiental (e-ISSN: 2236-1170)

Sim. Devido a idade avançada.

Sim. Exige muito tempo de dedicação.

Sim. Afeta negativamente a saúde.

Sim. Mas por conta da rentabilidade por

área não é possível.

\section{Por qual cultura substituiria}

Horticultura

Milho, soja ou arroz

Suínos ou gado.

Arrendaria ou venderia

Não sabe

\section{0 assunto já foi abordado}

Não

Sim, em palestras da AFUBRA, EMATER

e/ou Sindicato

Sim, pelo técnico da empresa
1

1

$4,76 \%$

2

$9,52 \%$

9

$42,86 \%$

2

$9,52 \%$

6

$28,57 \%$

3

$14,29 \%$

2

$9,52 \%$

8

$38,10 \%$

(1)

$23,81 \%$

4

$19,05 \%$

Por outro lado, $38,10 \%$ dos entrevistados admitem que, em virtude de menores preços oferecidos aos produtores, a atividade diminuiu muito sua lucratividade nos últimos anos. Havendo ainda uma parcela de produtores que justifica essa afirmação pelo fato de a atividade afetar de negativamente a saúde dos envolvidos (9,52\%). Neste sentido, Cavalcante e Pinto (2004) também verificaram uma crescente consciência por parte dos fumicultores sobre os riscos à saúde inerentes à atividade.

Uma vez que a totalidade dos produtores considera a hipótese de abandonar o cultivo de tabaco, entra em pauta a discussão acerca de qual cultura seria escolhida em sua substituição. Observa-se na Tabela 2 que 28,57\% dos produtores teriam como alternativa o plantio de milho, soja ou arroz. Aproximadamente 14,29\% deixaria a agricultura em favor da pecuária bovina ou suína. Além disso, entre as atividades menos citadas pelos entrevistados, tem-se a horticultura $(9,52 \%)$ e o arrendamento ou a venda das terras (9,52\%). No entanto, é interessante ressaltar que 


\section{REGETHFSM}

GUERRA ,KLINGER, DÖRR, v(10), no 10, p. 2327-2339, JAN-ABR, 2013.

Rev. Elet. em Gestão, Educação e Tecnologia Ambiental (e-ISSN: 2236-1170)

$38 \%$ dos agricultores não saberiam o que fazer se deixassem de ter no fumo a sua principal fonte de renda.

Ao considerar esta realidade, para que o processo de diversificação de culturas ocorresse de forma eficiente, seria necessária a orientação de instituições que facilitassem o processo de transição. Entretanto, quando questionados sobre o assunto, mais da metade dos produtores $(57,14 \%)$ afirmou que nunca houve abordagem a respeito .

Esta situação se torna ainda mais complexa à medida que o produtor, habituado a comercializar seu produto diretamente com as agroindústrias fumageiras, cria resistência ao desligamento da cadeia do fumo. Entretanto, conforme AFUBRA (2012), as regiões em que o tabaco é a base da economia já buscam alternativas para a diversificação e nestas $35 \%$ da renda dos produtores do setor já vêm de culturas como milho e feijão.

$\mathrm{Na}$ Tabela 3 são apresentadas as distribuições segundo a relação empresa/produtor, das quais cabe destacar que todos os entrevistados disseram negociar sua produção diretamente com as beneficiadoras de tabaco. Dentre estas, destaca-se a empresa Alliance One, responsável por $42,86 \%$ do mercado, seguida pela Souza Cruz (33,33\%).

No que diz respeito aos critérios utilizados no processo de contratação da empresa, há de se destacar a influência do elemento de tradição. Este, assim como as favoráveis condições de negociação, foi um fator determinante na decisão de $42,86 \%$ dos fumicultores. Além disso, para $85,71 \%$ dos produtores do município foram necessárias no máximo duas conversas para o fechamento do contrato, a informação mostra outra forte evidência da importância do elemento tradição nas decisões dos produtores em análise.

Ao se tratar dos elementos que regem tal relação contratual (Figura 3), verifica-se uma situação em que em $90,48 \%$ dos casos são as beneficiadoras de tabaco que definem o preço do produto, prestam assistência ao produtor (100\%) e participam ativamente do processo de seleção dos insumos $(95,24 \%$ de forma integral e $4,76 \%$ em consenso com o produtor). Além disso, também são estas empresas que definem a quantidade de insumos a ser empregadas na propriedade, onde em 33,33\% dos casos o produtor sequer preocupa-se em saber o montante utilizado.

Tabela 3. Distribuição de frequência de acordo com as variáveis referentes à relação empresa/produtor

Frequencia

Variáveis

Absoluta $(n=21)$

Relativa (\%)

\section{Empresa}


REGETAUFSM GUERRA, KLINGER, DÖRR, v(10), no 10, p. 2327-2339, JAN-ABR, 2013.

Rev. Elet. em Gestão, Educação e Tecnologia Ambiental (e-ISSN: 2236-1170)

Souza Cruz

07

$33,33 \%$

Alliance One

09

$42,86 \%$

Philip Morris

03

$14,29 \%$

Outras

02

$9,52 \%$

Por que escolheu

Tradição

$42,86 \%$

Oferece melhores condições

09

$42,86 \%$

Outros

03

$14,29 \%$

Número de conversas até fechar o

contrato

1 conversa

12

$57,14 \%$

2 conversas

06

$28,57 \%$

mais de 2 conversas

02

$9,52 \%$

Não respondeu

01

$4,76 \%$

Quem define o preço

Empresa

$90,48 \%$

AFUBRA

01

$4,76 \%$

Consenso entre empresa e produtor

01

$4,76 \%$

Quem presta assistência

Orientador da empresa

$100,00 \%$

Frequencia de assistência

Até 2 vezes por ano

02

$9,52 \%$

3 a 5 vezes por ano

04

$19,05 \%$

6 a 10 vezes por ano

03

$14,29 \%$

mais de 11 vezes por ano

12

$57,14 \%$ 
GUERRA ,KLINGER, DÖRR, v(10), no 10, p. 2327-2339, JAN-ABR, 2013.

Rev. Elet. em Gestão, Educação e Tecnologia Ambiental (e-ISSN: 2236-1170)

\section{Quem seleciona os insumos}

Empresa

Consenso entre empresa e produtor

Quem define o montante de insumos

Produtor

Empresa

Empresa e o produtor não tem

conhecimento da quantidade
07
20

01

$95,24 \%$

$4,76 \%$

$0,00 \%$

$19,05 \%$

$47,62 \%$

10

$33,33 \%$

Fonte: Elaborado pelos autores a partir dos dados primários da pesquisa.

Ao considerar estas informações, fica evidente o papel da fumicultura da região dentro do contexto do SAGs, já que esta constitui um elo de uma cadeia de produção estabelecida a partir da interação entre as agroindústrias processadoras de tabaco e os produtores de fumo. Esta estrutura coincide com o chamado Sistema Integrado de Produção de Fumo (SIPF), o qual é amplamente explorado na literatura relacionada.

Assim, através da ótica da ECT, pode-se classificar a estrutura de governança incidente no mercado fumageiro Vera-cruzense como um ambiente em que, dadas as dimensões dos atributos das transações, há um elevado grau de integração entre os atores. Esta situação se estabelece à medida que os fumicultores da região criam relações estáveis com a agroindústria. Tais relações permitem uma redução dos custos de monitoramento inerentes à produção, bem como dos riscos de incertezas entre os agentes, já que a atitude oportunista por parte de um dos atores implicaria na interrupção dos contratos. Este tipo de estrutura torna-se adequada uma vez que haja uma forte preocupação com os riscos provenientes das incertezas, bem como uma alta frequência das transações entre os agentes no mercado, características que já apontadas na presente pesquisa.

Outro fator a ser evidenciado é a situação de dependência em que se encontra o fumicultor em relação ao capital agroindustrial. Como é a beneficiadora de tabaco que determina tanto os preços pagos pelo produto, quanto dos insumos necessários à produção, o fumicultor acaba obtendo um menor retorno proveniente da cultura. Este cenário é ainda agravado pelo fato de que empresas que atuam na região constituem uma estrutura de mercado oligopolística, onde apenas duas empresas são responsáveis pela compra de $76,19 \%$ do fumo produzido, limitando a autonomia dos produtores no que diz respeito tanto às técnicas produtivas utilizadas, quanto à destinação final do produto.

\section{CONCLUSÕES}




\section{REGEIATFM}

GUERRA ,KLINGER, DÖRR, v(10), no 10, p. 2327-2339, JAN-ABR, 2013.

Rev. Elet. em Gestão, Educação e Tecnologia Ambiental (e-ISSN: 2236-1170)

Devido ao arcabouço histórico relacionado à região do Vale do Rio Pardo - RS, a maioria dos municípios da localidade acabou especializando-se na produção fumageira. Este é o caso do município de Vera Cruz, o qual tem na fumicultura a base de suas relações econômicas e sociais. Neste contexto, a partir da presente análise, foi possível reunir informações acerca do posicionamento do fumicultor do município em face à cadeia produtiva de tabaco. Assim, a partir dos dados da pesquisa foi possível constatar que o fumicultor vera-cruzense posiciona-se como um elo do chamado SIPF, onde os mesmos estabeleceram relações estáveis com a agroindústria, estando envolvidos na cultura de fumo há várias gerações.

Neste sentido, corrobora-se a hipótese de que as relações contratuais desta cadeia ocorrem por meio da integração entre os agentes. Entretanto, cabe destacar que a produção ocorre de forma pulverizada, baseada na agricultura familiar, intensiva mão de obra e estruturada em minifúndios, enquanto que, as empresas beneficiadoras de tabaco constituem uma estrutura de mercado oligopolizada, onde apenas duas empresas são responsáveis pela compra de $76,19 \%$ do fumo produzido na localidade.

Este cenário torna o fumicultor mais vulnerável aos choques de mercado, tanto no âmbito de oscilações nos preços do produto, quanto com relação a possíveis alterações na curva de demanda em virtude das campanhas antitabagistas que vem ganhando força no mercado. Entretanto, também foi constatado que, devido à estrutura minifundiária que dispõem o custo de oportunidade inerente à substituição do fumo, ou até mesmo à diversificação de culturas é muito elevado. Assim, apesar de todos os produtores entrevistados já terem cogitado a hipótese de abandonar o cultivo de fumo, a atividade ainda constitui sua principal fonte de renda. Por conseguinte, tal realidade coloca o fumicultor em uma posição de total dependência do capital agroindustrial.

\section{REFERÊNCIAS BIBLIOGRÁFICAS}

AFUBRA - Associação dos Fumicultores do Brasil. Relatório de Atividades Afubra 2011/2012. Santa Cruz do Sul: AFUBRA, 2012.

BOEIRA, S. L. Indústria de tabaco e cidadania: confronto entre redes organizacionais. Revista de administração de empresas, São Paulo, v. 46, n. 3, p. XX, 2006. Disponível em:

<http://www.scielo.br/scielo.php?script=sci_arttext\&pid=S003475902006000300004\&lng=en\&nrm=iso>. Acesso em: 31 Jan. 2013.

CAVAlCANTE, T. M.; PINTO, M. Considerações sobre Tabaco e Pobreza no Brasil: Consumo e Produção de Tabaco, in BRASIL. Ministério da Saúde. Organização Panamericana de Saúde, Tabaco e pobreza, um círculo vicioso- a Convenção Quadro de Controle do Tabaco: uma resposta, Brasília: Ministério da Saúde, 2004.

KARNOPP, E. Desafios e perspectivas para o desenvolvimento de uma agricultura familiar sustentável: o caso da região do vale do rio pardo (Brasil). Actas L.deV., 2003. Disponível em:

<http://www.wgsr.uw.edu.pl/pub/uploads/actas03/10-ERICA.pdf>. Acesso em: 31 Jan 2013. 
GUERRA ,KLINGER, DÖRR, v(10), no 10, p. 2327-2339, JAN-ABR, 2013.

REGETAUFSM

Rev. Elet. em Gestão, Educação e Tecnologia Ambiental (e-ISSN: 2236-1170)

MAPA. Ministério da Agricultura, Pecuária e Abastecimento. Intercâmbio Comercial do Agronegócio: Principais Mercados de destino, 2011. Disponível em: < www.agricultura.gov.br >. Acesso em: 31 Jan 2013.

VOGT, O. P. A produção de fumo em Santa Cruz do Sul, RS : 1849 - 1993. Santa Cruz do Sul: EDUNISC, 1997. 283 p.

SCHNEIDER, L. Estimativa dos Gastos dos Alunos da UFSM (2002): Aplicação da Amostragem Estratificada Proporcional. Santa Maria: UFSM, 2004. Monografia ( Especialização em Estatística e Modelagem), Universidade Federal de Santa Maria, 2004.

SCHOENHALS, M. et. al. Análise dos impactos da fumicultura sobre o meio ambiente, à saúde dos fumicultores e iniciaticas de gestão ambiental na indústria do tabaco. Engenharia Ambiental, Espírito Santo do Pinhal, v. 6, n. 2, p. 016-037, 2009. Disponível em: <http://www.scielo.cl/scielo.php?pid=S0250-71612006000200006\&script=sci_arttext>. Acesso em: 31 Jan. 2013.

SILVA, M. A. S. Segurança alimentar no meio rural:a experiência de formação de jovens rurais no Vale Rio Pardo, RS. CCNExt, Santa Maria, v. 2, n. 1, 2011. Disponível em:

<http://cascavel.ufsm.br/revista_ccne/ojs/index.php/ccnext/article/view/573/389>. Acesso em: 31 Jan. 2013. 